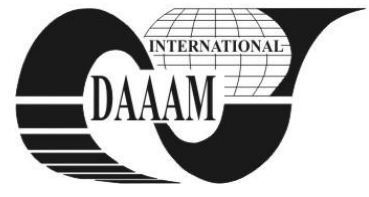

Annals of DAAAM for 2011 \& Proceedings of the 22nd International DAAAM Symposium, Volume 22, No. 1, ISSN 1726-9679 ISBN 978-3-901509-83-4, Editor B. Katalinic, Published by DAAAM International, Vienna, Austria, EU, 2011 Make Harmony between Technology and Nature, and Your Mind will Fly Free as a Bird Annals \& Proceedings of DAAAM International 2011

\title{
E - LEARNING APPLIED TO THE UNIVERSITY EDUCATION IN ENGINEERING
}

\author{
FENOLLERA, M[aria] \& GOICOECHEA, I[tziar]
}

\begin{abstract}
We have tried to apply the FaiTIC distance-learning platform to the Engineering Projects subject (Degree in Industrial Engineering) before it is affected by the Bologna Process. The aim was to gain experience, to apply lessons learned and to make a change in working methods and instructor's assessment. FaiTIC is based on the Claroline platform managed by the University of Vigo to reinforce traditional teaching. All available possibilities have been used to spread teaching material, to temporary link theoretical concepts and their practical application, to foster students' interest and to monitor their learning.
\end{abstract}

Key words: e-learning, engineer education, competences, free software, Claroline

\section{INTRODUCTION}

Background. When the current Study Program came into force in 2001, it led the Engineering Projects subject from 6 to 5 years and its 6 theory credits were split into 3 theory and 3 practice credits. This Study Program will be in force until the $5^{\text {th }}$ year where this subject is taught finishes. Simultaneously, the new European Higher Education Area (EHEA) degrees are being progressively introduced each year: 2010/2011 has been the first one in Industrial Engineering. Each degree will be 4 years long and this subject will be taught in the $3^{\text {rd }}$ course in some degrees and in the $4^{\text {th }}$ in others, depending on student specialization.

This work introduces the way to adapt to this new approach by applying e-learning techniques to this subject during the academic year 2009/2010 through a virtual learning environment based on free software (Claroline). The Engineering Projects was chosen by a significant number of students, about 220 from different specializations, all enrolled in the $5^{\text {th }}$ course and had 4 instructors to evaluate them. This framework changes significantly in the EHEA, since the students are already in different degrees by specialization from the $1^{\text {st }}$ year and groups are not so heterogeneous as they are now; furthermore, the number of students goes down considerably: we are referring to about 50 students.

Claroline is an Open Source e-Learning and e-Working platform that allows to build effective online courses and to manage learning and collaborative activities on the web. It was initiated in 2001 by the University Pedagogy and Multimedia Institute from the Catholic University of Louvain, Belgium. The Claroline Consortium was born in 2007 and the University of Vigo was one of its 5 founder members. It stands out for being user-friendly as opposed to other kinds of platforms (Plantak et al., 2010; Casar, 2006; De Henao, 2007).

We have decided to use this platform called FaiTIC since it gathers specific and particular characteristics of Content Management Systems (best known as CMS), such as being totally dynamic, highly configurable, versatile and simple when it comes to modifying its contents. It allows to publish documents in any format (.doc, .odt, ppt, pdf); administrate and model discussion forums, both public and private; to administrate listings of reference links; create study groups; make practice exercises; structure and administrate an agenda of events, tasks and deadlines; control course users or students; administrate each course instructors and teachers; handle students' deliveries (documents, tasks, works, etc.); manage and store the chats that instructor and students can establish; complete follow-up by means of students enrolment statistics; and assess through multiple choice system. In addition, the platform has been used in this subject since 2005 because of its flexibility and ease of action but only as a repository or for students to upload their works.

\section{E - LEARNING STRATEGIES DESIGN}

In order to plan any type of formative action, purpose is the first thing that we have to establish. Aims must be wide enough as to include not only aspects related to the subjects' knowledge, but also to other learning areas, such as those allowing to acquire general or cross-curricular competences and more general skills of diverse types. Among those types as: to form a part of a virtual community of work, to take part in collective knowledge construction, to collaborate in the creation of interpersonal networks that contribute to motivation, to use tools adequately or to master basic concepts and to penetrate the basic procedures of the subject.

The study group was made up by 217 students and 4 instructors. The subject is split into fifteen theoretical areas of 2 hours each and four practice topics, two 3-hour and another two 9-hour lectures. The theory lectures last 2 hours and lab practices last 3 hours. Learning, group work, time management, oral and written communication are practised. Work is also distributed throughout the four-month term, avoiding usual final efforts.

The presentation of objectives, methodologies and procedures for following up on the subject was done the first day of class. Materials for study and complementary reading can be found on the platform in an organized way with the following formats: presentations, text files, rules, standards, latest news, drawings, images, videos, websites, etc. Teaching and assessment activities calendar is included in the tutorial published in the virtual learning environment, as well as the rest of teaching and assessment material that was followed from that first on-site class through Claroline online learning management system. A series of activities related to the assessment of competence is also included, as well as a forum to clear up any doubts. They can also be asked by e-mail or in person to the subject instructors.

Some assessment procedures have been established to check that competences are reached:

- Online exercises: their degree of difficulty is fixed according to the student's specialization. The configuration of these exercises is very variable; they can request a simple argument from the student about questions of current issues importance presented by the teacher, or can present videoconferences and scientific works to the student in which contradictory information is included, requesting opinions and more complex argumentations.

- Multiple-choice test in practical lectures, in labs, regarding key topics. Enable online assessment for a limited period of 
time and for all students at the same time. The aim is both to confirm the acquisition of some specific knowledge and to attain some information search and selection skills.

- Written report about a topic for study proposed by the instructor made through cooperative group work. It basically involved searching for information and creating a document in electronic format in which all group members participated through a suitable task distribution and keeping a uniform format and structure.

\section{RESULTS AND CONCLUSION}

As it has been exposed, the teachers have set up different and varied activities and learning methods that will imply overcoming fear regarding the use and command of TICs and to put learnt concepts into practice (Pino, 2008).

The main achievements are as follow:

(1) Very good academic results have been obtained in this subject with students' follow-up and success rate close to 95\% (figure 1). The percentage of students that did not take the final exam is in keeping with those students not following the continuous assessment procedure proposed in this experience.

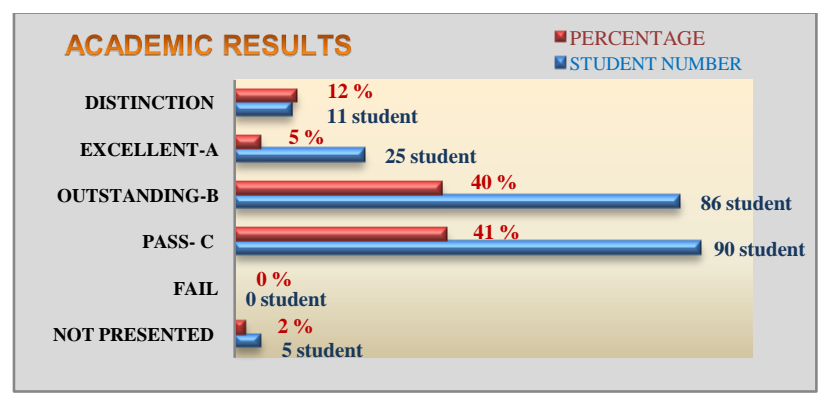

Fig. 1. Results for the 2009/2010 Academic Year

(2) The instructor has been witness to the participation of students in the activities developed. Figure 2 shows how the use of tools have increased each year; "documents and links" becomes the most evident, almost tripling its value. As FaiTIC statistics reveal the online exercises, forums and wikis are activities that stir students into action, but with a very irregular follow-up by the student body.

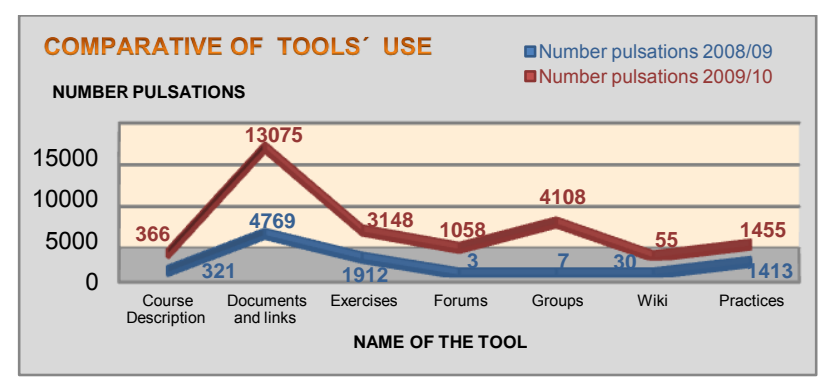

Fig. 2. FaiTIC statistics

(3) The e-Learning platform allows to track each student individually, as well as to set up group or individual virtual tutorials, thus serving each student's needs and respecting their learning pace (Rosu et al., 2010).

(4) The scheduled three-hour working sessions, particularly for labs, makes it easier for students to be immersed in the topic for longer periods. These experiences made them more aware of the context in real projects, where there is no jumping from one issue to another every hour.

(5) There was not a specific tutor by group, the four instructors tutored all the groups; this partly arose from teaching by topics instead of by groups. What is claimed is to unify the assessment criteria for contents, improving the quality of education with the best specialists in each area. This implied a good coordination among them, which was hard in the beginning, since the students tended to repeatedly ask all the instructors about the same topics, turning to the one that made their work easier. Instructors' weekly meetings were set to sort these initial difficulties out.

(6) Learning, group work, time management, oral and written communication are practised. Avoiding typical end-of-term efforts, work is also distributed throughout the term.

On the contrary, some negative aspects bring to light:

(1) At personal interviews in tutorials students complained about this new way requiring a bigger effort.

(2) They also mentioned the problem of not having enough time; the documents included in the virtual environment could seem excessive when compared to those of the traditional method.

(3) The change in the tutoring method (the instructor provides orientations, references, bibliography, aiming for the student to obtain answers himself) was regarded by some students as lack of involvement.

Despite the difficulties, the final result was very satisfactory. As a whole, e-Learning facilitates the process of education- learning by opening a new educational scene where instructor-student modify the relations, the learning is adapted and the diffusion of the knowledge is increased. In fact these strategies allow to trace students' progress in detail; make interpersonal communication with information exchange and dialogue; improve tutorial and teaching functions; collaborative research sharing information and creating templates; access information and learning contents, and recovering traditional teaching through the access to the contents of the subject, exercises and bibliography.

This 2010/2011 academic year several online initiatives are being carried out, such as discussion and doubt forums, work and presentation templates and self-assessment tests. Additionally, an assessment table or rubric is being designed to assess cross-curricular competences pursued.

\section{ACKNOWLEDGEMENTS}

The authors would like to thank all the instructors from Engineering Projects Area, who are behind this initiative.

\section{REFERENCES}

Casar, A. (2006). Claroline at the University of Vigo in Spain, adaptations and use. ACCU2006, Spain. Available from: http://www.claroline.net/accu/accu-2006-2.html

De Henao, T. (2007). Claroline: an Outsider's Perspective. Universidade de Vigo. ACCU2007, Spain. Available from: http://www.claroline.net/accu/accu-20072.html.

Plantak, D.; Kirinic,V. \& Klicek, B. (2010). A Comparison of Usability Evaluation Methods for e-Learning Systems, Chapter 27 in DAAAM International Scientific Book 2010, pp. 271-288, B. Katalinic (Ed.), DAAAM International, ISBN 978-3-901509-74-2, ISSN 1726-9687, Vienna, Austria

Pino, M. (2008). Aplicaciones de herramientas de e-learning a la docencia presencial. Revista de Formación e Innovación Educativa Universitaria (REFIEDU), ISSN 1989-0257. Vol. 1, No 4, 87-95 (2008) 87. Universidade de Vigo, Spain

Rosu, S. M.; Dragoi, G.; Rosu, L. \&Guran, M. (2010).Virtual Enterprise Network Solutions to Support E-learning Sites Development, Chapter 63 in DAAAM International Scientific Book 2010, pp. 725-742, B. Katalinic (Ed.), DAAAM International, ISBN 978-3-901509-74-2, ISSN 1726-9687, Vienna, Austria 